\title{
Consideration on Poverty Problem of Young People in Industrialized Countries and Their Solutions
}

\author{
Daisuke Hirahara \\ Kagoshima Medical Professional College, Kagoshima-Shi, Japan \\ Email: ffieldai@gmail.com
}

How to cite this paper: Hirahara, D. (2018) Consideration on Poverty Problem of Young People in Industrialized Countries and Their Solutions. Modern Econo$m y$, 9, 203-212.

https://doi.org/10.4236/me.2018.91013

Received: December 30, 2017

Accepted: January 22, 2018

Published: January 25, 2018

Copyright $\odot 2018$ by author and Scientific Research Publishing Inc. This work is licensed under the Creative Commons Attribution International License (CC BY 4.0).

http://creativecommons.org/licenses/by/4.0/

\begin{abstract}
Increase of irregular workers called working-poor is a problem. This unstable employment makes the poor more poverty. The possibility that a simple work is deprived by the development of artificial intelligence is increasing. From this background, restructuring of social structure and policies become important. In Japan, as the declining birthrate and aging population progresses, there is concern that more people need medical care and nursing care services, so increasing social security expenses is also a problem.
\end{abstract}

\section{Keywords}

Worker, Poor, Artificial Intelligence, Medical, Nursing, Education, Working-Poor

\section{Introduction}

It is the United States that the word "working-poor" was first born. Robert Hunter, Jane Adams, W. E. B. Dubois, a thinker of the era when society and politics were greatly reformed between the 1890s and the 1920s, and they thought that "the one underlying poverty is not equally given to social opportunities", and because of discrimination, poor people who cannot escape from poverty how much they work will be called "working-poor".

The working-poor that is a problem in Japan is not caused by discrimination. However, Japan is the second largest relative to the US in terms of relative poverty among developed countries. For many years since the end of World War II, the majority of people in Japan thought that they were middle classes who were neither poverty nor rich, and they were said to be "one hundred million 
total midstream society" that there is not so much difference between the people. Also, there was no concept that it would be poverty even while working. However, in Japan today, I think that the poor are gradually increasing due to the effects of economic conditions and employment conditions. The poor life of the working-poor is often taken up in media such as television, but young people's working-poor, in particular, is a serious problem. Of course, such people cannot expect a stable life, so marriage, raising children, and even independent living from parents are becoming difficult. It is said that youth of such poor people is increasing every year.

In this paper, after grasping the current situation of working young people's working-poor, think about the problems that young people working as working poor have, and think about the problems and influences on society caused by that as well. With that in mind, I will examine whether there are solutions to young people's working-poor or if solution is impossible.

\section{Present Status of Young Working-Poor}

As mentioned at the beginning, although the term "working-poor" was born first in the US, the term "working-poor" has become established in Japan in recent decades. Working-poor refers to a situation in which salary is low and life is difficult, although working full time, except part-time and short-time part-time jobs. There is no prospect of raising salary no matter how much it works, and the working state that only physical strength wears down is the working-poor. Then, what is the specific condition of small salary? It is defined as being under the level of welfare protection or difficult to maintain life. However, there is no formal definition yet for taking statistics.

\section{On-Regular Workers and Poverty}

If you think about the problem of working-poor, you also need to think about non-regular workers and poverty. Because these three elements are closely related. First of all, the problem of non-regular workers is not limited to the problem that wages that can be received are lower than regular employees. Opportunities for education are overwhelmingly small compared to regular employees. According to the present situation and problems of "non-regular employment" announced by the Ministry of Health in Japan, Labor and Welfare, the number of establishments implementing education and training for non-permanent employees is about half of full-time employees.

Moreover, most companies called "Black Company" are based on the premise that employees are thrown away. In addition to not having opportunities for education, they abuse their employees until they cannot work. A mechanism is created to have you work with low wage until overworking and then voluntarily quit. Author Okawa Machiko wrote such a state in the following words. "The younger generation becomes, the job is in the same level as regular employees despite employment form is non-regular [1] [2]. 
Companies that hire non-regular employees can reduce their labor costs and boost their profits if forcing such labor is forgiven. Not only can you always secure labor at a certain cost, it is not a regular employee, so there is no responsibility to protect employees. Furthermore, if you hire a non-regular employee, you can be dismissed practically legitimately without any problems when judging it is unnecessary. Then, it is increasingly advantageous for the company. However, it seems natural for non-regular employees to become a harsh environment. In this way, the problem of non-regular employment is not limited to a small salary. The malicious working environment is also a problem. And because there is no opportunity for education, it is very difficult to raise salary, or skill up by changing jobs.

The problem of non-regular employment is not limited to this. After graduating from university, it seems that there is no problem if you get a job as a regular employer in a major company. However, if you get employed as a non-regular employee even once after graduating from college, the possibility that it will be adopted as regular employment in the future life will be low only by that. The same applies to those who have continued to work with regular employment. If you retire from a company that got a job as regular employment for some reason, once you work with irregular employment it is difficult to get a job as regular employment again. Even with non-regular employment, there were opportunities to become regular employment by acquiring state qualifications with fewer holders, or acquiring the skills of underutilized work. However even in professionals such as lawyers and physical therapists who were once worthy, modern day is saturated.

\section{Problems of Young People in Working Poor}

The problem of young people who are working-poor is more serious than looking from the outside. The reason is the working environment. As the term "black company" became commonplace, extortion of harsh work environments for workers by large companies may have been purged to some extent. In other words, the working environment that graduated from a top university and entered the company with a new graduate was improved. However, the improvement does not extend to most SMEs. Rather it may be getting worse. According to news reported on television, there are people who are suffering from mental problems due to harsh labor, those who die from overwork. Also, in the workplace where working-poor is created, there are things that it is dare to make such an environment. In other words, it is recognized that self-worth is low due to harsh labor and low salary, and sometimes it tries to impair the energy to change jobs to other workplaces. According to Kenichiro Akiyama's book "Real feelings of black-company's managers" [2], one investment company has made it clear that "training is being implemented to impose submission attitude." In other words, once entering a working environment that falls into a working-poor, there is a possibility that malicious mind control is being carried out. 
Therefore, even those who have been healthy and bright student days will become working-poor when they become accustomed to the environment. Also, the problem is that black-companies do not seem to provide a severe work environment on a superficial basis. Some companies use commercials to give healthier and brighter images to consumers more and more. Therefore, the parent's generation encourages young people to find employment in companies that are likely to be economic and profitable. And even if the working environment is actually harsh, in most cases they will not believe. "Young people in recent years have no patience", they clear up in this single word. In this way, the cause of creating a working-poor is also caused by the manager who does not recognize the worker as a person but simply recognizes it as a cost. And it is reality that such companies are getting very large. Company management is not easy any time. In this way, there are companies that cannot secure profits unless we do not do the harsh methods. Companies that cannot afford to operate are indispensable labor force to work long hours with cheap wages. Therefore, as Takashi Kadokura wrote, there is a high possibility that the company is not a Japanese in the future, and it is likely to actively hire foreign workers who work at lower wages. What will become necessary in the future is a foreigner who performs simple labor that will undertake the work of $3 \mathrm{~K}$ (tight, dirty, dangerous) that Japanese hate" [3].

Management is also desperate for cost cuts. As a result, it seems that the tendency to consider workers as a cost rather than a person has become established. Indeed, in the "real feelings of the manager of the black-company", the president who has passion for emerging about how much it is possible to create a mechanism to make part-time jobs "service-overtime work" (overtime work without paying wages) appears. Although it is an extreme expression, the real feelings of the manager of a malicious black-company do not want to pay salary. At the current Diet session, deregulation of working hours is being debated. When this is realized, managers who consider workers as cost will be delighted. Given the current recessionary Japanese economy, it is unlikely that such a black-company will disappear from the world.

\section{Living Environment Problems}

As I mentioned earlier, it is not easy for a person who became a working-poor to get out of that situation. Therefore, everyday life becomes more and more difficult. As a result, there are young people who cancels rental apartments to borrow. Usually, when you lose your house you will be homeless, but not everyone sleeps in the park. Some people sleep at internet cafe. Such people are called "net cafe refugees". In this state, it is more difficult to escape from the working-poor. In re-employment, if there is no address it is likely to be dropped at the stage of document selection. However, the cause of becoming an Internet cafe refugee is not always the only on the working-poor. Because if it is difficult to pay the rent, there is a way to share the room with a friend, or to become a care of relatives, 
brothers, family. If you have personal relationships such as families, relatives, friends who live near you, you will never become an Internet cafe refugee. Therefore, when becoming a working poor, there is a need to focus consciousness on maintenance and construction of human relationships even without money. It is because there is a possibility that such human relations will help themselves.

However, there is a case that a person who was popular in school days suddenly no longer has human relations after finding employment. Most of the reasons are overwork due to employment, or hardship. The problem of working-poor and black company cannot be separated. As I mentioned earlier, black-companies dare to establish workers' self-reliant consciousness and a mechanism to lower self-esteem. For example, if there were shops that adopted unfavorable uniforms in the restaurant industry, there is a high possibility that an intention to reduce workers' self-esteem is included among them. And by employee training and education, gradually impair self-reliance and let it obedient. In fact, those who have long worked for black companies can be very ruthless personality. It changed as a result of attempting to adapt to a black-company. In this way, the more you try to adapt to the malicious work environment, the more heart and mind will be exhausted. Not only that, but also the personality changes.

If the spirit and the body are exhausted, the risk of getting sick is increased. In the book by Takashi Kadokura, a case of young people who caused sudden deafness due to overwork was introduced. "I went to the hospital in a hurry, the doctor diagnosed as sudden deafness. Apparently it seems that it has become sudden deafness "due to overwork, stress, sleep deprivation [3].

When you get sick like this, your sense of human relationship will change as a matter of course. People who were bright, cheerful and sociable during the school days get tired of working, feeling human relations troublesome. And as human relationships become thinner, they become more and more lonely. In this way, the working-poor may also cause the collapse of human relations. And when they get a job in a city apart from their hometown, this situation is highly likely to happen. For example, a person whose parents have a home in Tokyo has a way to return to their parents' house even if they get employed in a blackcompany in Tokyo. However, there are no such places in rural people. If there are neither friends nor their families around them, they will feel more poverty. Even if they do not have the money, they can help each other if there are good friends and family members close by. However, without money or relationships, it makes you feel hopeless, making it harder to get out of the working-poor.

\section{Health Condition Problems}

The problem caused by working-poor is not only economic and living environment. Working-poor also has a significant effect on health. First of all, if it becomes a working-poor, it is inevitable that the money that can be used for food expenses becomes insufficient. Then, many people take similar behavior and 
thought patterns. It is as follows.

- Trying to buy food at a cheaper amount of money.

- Eating habits emphasis on quantity rather than quality.

- To become conscious of not using money rather than health condition.

This behavior and thought pattern may seem to have no problem at first glance. However, in fact this thought pattern has a big problem. That means that in modern Japan, the risk of impeding health by having such a thought pattern becomes infinitely high.

And further problems will happen even after actually getting sick. Basically, daily living expenses are not enough when it becomes a working-poor. As a result, some people are delinquent about health insurance premiums. If health insurance is not applied, medical expenses inevitably become expensive. That amount may exceed 10,000 yen to 20,000 yen for one examination and 100,000 yen for one night's hospitalization. In the state of working-poor, they cannot pay such amount. Therefore, once they get sick, it gets worse and there is a possibility that they will lose physical condition more and more. In case of loneliness, such health problems become more serious.

\section{Social Problems Caused by Increasing Number of Working-Poor}

Working-poor is not only personal problems. The increase in working-poor may cause social problems. So what kind of problems will be caused by the workingpoor? The first thing that can be thought is an increase in crime. It can be understood by looking at the state of poor areas in various countries around the world, but people are likely to lose their common sense judgment power when they are in poverty.

Because in capitalist society poverty is directly linked to the crisis of the existence of life. If there is no food, humans will starve and die. In the past Japan it might not be possible to think such a thing, but if you become an elderly person and you lose your physical freedom and become poor, that possibility will be sufficient. Therefore, if the number of working-poor increases, crime for living may increase.

The problem caused by the increase in working-poor is not limited to that. There is a high possibility that the widening of inequality will become bigger in the future. Children born to poverty families have been in poverty since they were born. Currently, one in six elementary school students is already in poverty. Children born to families who do not have enough economic power to eat breakfast go to school without eating breakfast. In that case, children do not have physical strength or concentration, so overall skills such as athletic ability, intellectual ability, thinking ability, etc. are inferior to general children. As a result, it becomes more difficult to go on to higher education and the possibility of getting a good job is reduced. And even if you start working, you work at a low wage in a position that is used by people, and it is highly likely that poverty will continue to chain beyond generations. As a result of such an increase in families, 
the role of the school teacher is also changing. Some health teachers in elementary school go to work early in the morning and provide breakfast as a result of seeing the miserable situation of children. The meal's ingredients use the school lunch surplus. This like, If more adults acting in good faith increase, the children may be saved, but it will not be a fundamental solution to the problem.

On the other hand, children born in wealthy families do not enroll in elementary schools of Japan which are considered to have a low education level globally. They live abroad and enter the elementary school there, but they have entered a private school where American schools or Montezori were introduced, and receive higher quality education. Children who have received such high-quality education are highly likely to be active after starting the work. And their descendants will become wealthier.

Thus, the increase in working-poor is also the cause of promoting a disparity society more. As the polarization of the rich and the poor becomes more pronounced, there is a possibility that the Japanese will be divided clearly like the aristocracy class and the slave class of medieval Europe.

\section{The Effect of Progress of Declining Birthrate}

As the number of working-poor families increases, the problem also affects the declining birthrate. Because, as the working-poor became generalized now, there are also trends that childbirth regards as luxury. Young couple who are in need of daily living are not easy to prepare for childbirth and childcare expenses. However, when a young couple is married, they will have nature and children. Therefore, there are many families who are going to give birth even if they cannot afford economically. As a result, families become more severely in poverty situation due to child-rearing expenses, expenses for educational expenses, etc.

The problem of poor families is not simply economic pains. When economically hardships, the spiritual margin is gone by all means. As a result, the couple's fight increases and trust is easily lost. Because it is a poor household, families need to cooperate, but the reality is not so easy. People will tend not to think about other people if they lack mentality due to poverty. Also, people try to relieve stress. It would be the worst if stress relief became a way to use children. In other words, abuse may occur. Children who have been abused once will become more likely to abuse their children when becoming an adult. That family may have such a negative chain for many generations in the future. This is the case when giving birth to a child, but in most poor families there are cases where you are not thinking about making a child in the first place. For economic reasons they are giving up having children. Increasing the number of working-poor will increase such poor households. And thinking in terms of the country of Japan, the declining birthrate will be advanced.

\section{Impact on Japan's Economy}

As the number of young people in the working-poor continues to increase, there 
is a possibility that future Japanese economy will be seriously damaged.

If the current working poor problem is not solved and if the government is promoting policies that will hurt the poor by lowering corporate taxes and increasing consumption taxes, the possibility of the Japanese economy failing is extremely high. And as of 2017, there may be industries with some economic conditions somewhat better due to the entry of foreign tourists, but I do not think it will last forever. Also, through the Olympic Games, large public funds are flowing into the construction industry, but it is not a Japanese company but flowing in global company. Taxes paid by Japanese citizens are not flowing to the private sector through government agencies, but they are flowing out overseas. It is unlikely that the state that is in such a state will continue for a long time in the future. If there is not fundamental change in not only the problem of working-poor but also the policy of running the country of Japan, it can be said that a very harsh future is waiting.

\section{Conclusions}

The working-poor that is a problem in Japan is not caused by discrimination.

The problem of working-poor is not happening only in Japan. Similar problems occur in countries around the world, and countermeasures are being taken. So, what kinds of measures are taken in various countries around the world? First, let me introduce the state of Korea next to Japan. Before long before the problem of the working poor is taken up extensively in Japan, in South Korea, measures are taken for working-poor. In other words, in Korea the problem of the working-poor became obvious earlier than Japan. The social structure that continues to exploit the next generation has stalled faster than Japan. So, what kind of measures did Korea actually take? One thing to be sure about first is that Korean non-regular workers are more active than Japanese non-regular workers. In Korea, from around 2000 gradually the movement of non-regular workers is developing. In addition to regular workers, labor unions are formed in non-regular workers and they are acting on their own to protect their position, such as implementing a sustained strike. As a result, there are enacted laws. That's the Non-Regular Employment Protection Act [4]. Among them, rectification of discrimination treatment and worker protection are stipulated. Support for public non-regular workers is not limited to that. The basic welfare protection system has also been greatly improved, and even if it is not below the minimum standard of living, the right to receive protection expenses is allowed. Although such aggressive measures have been taken, the problem of working-poor is not solved. Legal amendments, which are hurting for irregular employment, such as worsening of the minimum wage law, also overlap, and the lives of non-regular workers are not greatly improved [5].

Then, what measures are taken by the US with the same working-poor problem as Japan? The working-poor problem in the United States has started to draw attention since the late 1980s. Then, what is the specific measure? The first 
measure considered in the United States was raising the minimum wage. However, the situation of the working-poor has not dramatically improved by that measure. North Carolina State is promoting industry-university cooperation, trying to create jobs and trying to solve the problem. In the United States, "food stamps" are provided to working-poor and poor people. Food stamps are programs provided by the Federal Department of Food and Nutrition. To briefly explain this, it is free distribution of food. Although this does not mean that the working poor have been resolved, it seems to be a policy with social value, at least in the sense that the poor have exceeded the hunger [6].

Next let's introduce about UK's working poor measures. In the UK, supporters who introduce vocational training are not in the facility but in the city. And they are doing steady activities such as confirming the presence of work after speaking to young people in town. And, if he do not work, or if he works but have trouble such as being in working-poor, they will conduct hearings and introduce occupations. Such efforts may be one of very effective countermeasures because it is an initiative that not only measures against working-poor but also improves employment situation throughout the UK.

In this way, the problem of the working-poor does not occur only in Japan. Similar problems occur in countries around the world, each of which is taking countermeasures.

From here, we will consider ingenuity to solve the problem of poverty. As of 2017, a tertiary artificial intelligence boom is ongoing. I thought that one of the solutions to the current poverty problem was artificial intelligence. At the moment, artificial intelligence is considered to be a threat as a person depriving work. Artificial intelligence does not take away all work but deprives a simple job [7]. This means that humans are released from simple tasks. Artificial intelligence does not get tired and works quietly without complaining. Artificial intelligence is efficient. Artificial intelligence may increase wealth [8]. The state can redistribute the wealth created by artificial intelligence. In advanced countries where the declining birthrate and aging population will progress in the future, more people will use medical care and nursing care. This squeezes medical expenses and expands the welfare budget. In developed countries, there is a high possibility that demand for work related to welfare will increase. This is because communication between people is important for medical care and nursing care. In order to solve the poverty problem of young people from these things, it is to acquire specialized skills in medical care and nursing care. I want you to realize redistribution of educational strengthening as a young man's medical professionals, and the wealth of artificial intelligence as a policy. I think that the poverty problem will be solved [9].

\section{References}

[1] (2010) The Essence of Japanese Type Working-Poor: Okawa Machiko: Iwanami Shoten.

[2] (2014) Black-Company Manager’s Thinking :Akiyama Kenichiro: Fusosha. 
[3] (2008) Is the Working-Poor Self-Responsible?: Takashi Kadokura: Yamato Shobo.

[4] Current Status and Issues of "Non-Regular Employment" (Ministry of Health, Labor and Welfare).

http://www.mhlw.go.jp/file/06-Seisakujouhou-11650000-Shokugyouanteikyokuhak enyukiroudoutaisaku-

bu/0000120286.pdf\#search=`\%E5\%8E\%9A\%E5\%8A\%B4\%E7\%9C\%81+\%E9\%9D\%9 E\%E6\%AD\%A3\%E8\%A6\%8F\%E5\%8A\%B4\%E5\%83\%8D\%E8\%80\%85+\%E5\%B9\% B3\%E5\%9D\%87\%E8\%B3\%83\%E9\%87\%91'

[5] Sokkun, Y. and Koichi, P. (2009) Korea Working-Poor 880,000 Won Generation: Akashi Shoten.

[6] Special Feature: Problem of Gaps $\bullet$ Measures against Working-Poor in the USFederal Policy Recommendations by Think Tank, and Trends in North CarolinaIbi Mieko.

http://www.ndl.go.jp/jp/diet/publication/legis/236/023611.pdf\#search='\%E3\%82\%A 2\%E3\%83\%A1\%E3\%83\%AA\%E3\%82\%AB+\%E3\%83\%AF\%E3\%83\%BC\%E3\%82\% AD\%E3\%83\%B3\%E3\%82\%B0\%E3\%83\%97\%E3\%82\%A2\%E5\%AF\%BE\%E7\%AD\% 96'

[7] Kokina, J. and Davenport, T.H. (2017) The Emergence of Artificial Intelligence: How Automation is Changing Auditing. Journal of Emerging Technologies in Accounting, 14, 115-122. https://doi.org/10.2308/jeta-51730

[8] Brynjolfsson, E., Rock, D. and Syverson, C. (2017) Artificial Intelligence and the Modern Productivity Paradox: A Clash of Expectations and Statistics. National Bureau of Economic Research, NBER Working Paper No. 24001.

[9] Siau, K. (2017) Impact of Artificial Intelligence, Robotics, and Automation on Higher Education. Twenty-Third Americas Conference on Information Systems, Boston. 